\title{
FREQUENCY OF HEPATOCELLULAR CARCINOMA AND ASSOCIATED SOCIO- DEMOGRAPHIC FACTORS IN TREATED PATIENTS OF CHRONIC HEPATITIS C
}

\author{
Rabia Tariq, Anum Abbas, Farrukh Saeed, Zafar Ali Qureshi \\ Pak Emirates Military Hospital/National University of Medical Sciences (NUMS) Rawalpindi Pakistan
}

\begin{abstract}
Objective: To look for frequency and associated socio-demographic factors of newly diagnosed patients of heaptocellular carcinoma (HCC) among patients treated adequately for hepatitis C infection.

Study Design: Correlational study.

Place and Duration of Study: Gastroenterology Department, Pak Emirates Military Hospital Rawalpindi, from Nov 2017 to Oct 2018.

Methodology: This analysis was performed on 170 patients treated effectively for hepatitis $C$ with standard antiviral therapy at our hospital. They were followed up for two years after the sustained viral response has been achieved. Ultrasonography was done in all cases and contrast enhanced computerized tomography scan done on patients who were positive on ultrasound. Factors like age, gender, genotype of heaptocellular carcinoma, presence of cirrhosis and model for end-stage liver disease (MELD) score were related with presence of heaptocellular carcinoma among the target population.

Results: Out of 170 patients included in final analysis 121 were male, 49 were female. About 53 patients were diagnosed as suffering from heaptocellular carcinoma while 117 were negative for that. Thirty six patients had cirrhosis while 134 non cirrhotic. After applying the binary logistic regression genotypes other than 3, high model for end-stage liver disease score \& presence of cirrhosis had a strong relationship with presence of heaptocellular carcinoma among the patients treated for hepatitis $C$ virus.

Conclusion: Physicians and patients cannot ignore the possibility of a malignant outcome even after successful treatment of hepatitis C. Local protocols should be set for screening especially the high risk cases even after treatment of hepatitis $C$ virus with special attention to patients with genotype other than 3 , cirrhosis \& high model for end-stage liver disease score on follow up visits.
\end{abstract}

Keywords: heaptocellular carcinoma, Hepatitis C virus, Incidence, Treated.

This is an Open Access article distributed under the terms of the Creative Commons Attribution License (http://creativecommons.org/licenses/by/4.0), which permits unrestricted use, distribution, and reproduction in any medium, provided the original work is properly cited.

\section{INTRODUCTION}

Liver diseases have been one of the major causes of mortality and morbidity in all the populations of the world 1 . Types of diseases vary according to the geographical distribution as well as other social and demographic factors ${ }^{2}$. Alcoholic liver disease rank high in the west while viral infections constitute most part of the liver diseases in third world countries including Pakistan ${ }^{3}$. Multiple types of viruses have been studied in this regard which can affect the liver in acute or chronic manner. Hepatitis $\mathrm{C}$ is most notorious for this problem and linked to the phenomenon of cirrhosis and end stage liver disease in most of

Correspondence: Dr Rabia Tariq, Resident Gastroenterology, Pak Emirates Military Hospital, Rawalpindi Pakistan

Received: 08 May 2019; revised received: 11 Jun 2019; accepted: 21 Jun 2019 the third world countries 4 . It has various genotypes and affects the liver parenchyma in a lot of ways leading to cirrhosis, liver failure or hepatocellular carcinoma 5 .

GI tract harbors various kinds of malignancies with variable prognosis. Hepatocellular carcinoma is one of these which pose a lot of burden on the patient as well as the health care system ${ }^{6}$. It is a fairly common malignancy in all parts of the world including the subcontinent ${ }^{7}$. Multiple etiologies have been linked with the incidence of this devastating illness. Cirrhosis is one of the most important risk factors linked to this cancer ${ }^{8}$. Hepatitis $\mathrm{C}$ infection is the commonest cause of cirrhosis in our set up ${ }^{9}$. This phenomenon usually occurs among the patients who do not receive the antiviral treatment or receive it very late or has a 
genotype with poor prognosis. Patients who get timely and adequate treatment of the HCV infection and show sustained viral response are believed to be protected against the cirrhosis and formation of $\mathrm{HCC}^{10}$.

Studies in the recent past have shown different results as compared to the common perception that once hepatitis $\mathrm{C}$ has been treated effectively patient has no risk of transforming into cirrhosis or HCC. A recent meta-analysis of various studies concluded that patients even after receiving a sustained viral response remain at a high risk for the development of fibrosis and HCC ${ }^{11}$. Another similar review concluded that there must be some mechanism at molecular level in the liver parenchyma which predisposes these individuals towards HCC despite adequate treatment with direct antiviral therapy ${ }^{12}$. A recent study done in Germany concluded that around 3 percent of the patients who were treated for $\mathrm{HCV}$ developed HCC in follow up time of around an year. Presence of cirrhosis was strongly linked to the diagnosis of hepatocellular carcinoma among the patients ${ }^{13}$. Study done in Sweden also replicated similar findings by following the patients for around eight years highlighting the fact that cirrhotic patients remain at a higher risk for developing HCC even after the achievement of sustained viral response ${ }^{14}$.

One of the major health issues of our country is hepatitis $C$ infection and patients suffering from conditions related to this infection. These conditions range from being silent carrier of the virus to the patient with metastatic HCC. Most of the patients belong to rural background and once they have achieved sustained viral response and get the reassurance from the treating physician they never come back till develop full blown illness again. Therefore adequate knowledge among the physicians is necessary in this regard. No local study has been performed to follow up these patients and observe the delayed outcome after the achievement of sustained viral response. This study was planned with the rationale to look for the frequency and associated sociodemographic factors of newly diagnosed cases of hepatocellular carcinoma (HCC) among the patients treated adequately for hepatitis $C$ infection at Pak Emirates Military Hospital RWP.

\section{METHODOLOGY}

This correlational study was conducted at the gastroenterology unit of Pak Emirates Military hospital Rawalpindi from Nov 2017 to Oct 2018. Non-probability consecutive sampling technique was used to gather the sample for this research. All patients between the age of 12 and 70 years who had been suffering from hepatitis $C$ infection and received a sustained viral response were included in the study and followed up for two years. Patients with any cause of liver disease other than hepatitis $C$ were not included. Patients with comorbid Hepatitis B infection were also not included. Patients included received standard direct anti-viral therapy according to the international guidelines and achieved sustained viral response at 24 weeks of treatment ${ }^{15,16}$.

Model for End-Stage Liver Disease (MELD) Formula used was: $0.957 \times$ Loge (Creatinine $[\mathrm{mg} / \mathrm{dL}])+0.378 \times$ Loge (Total Bilirubin [mg/ $\mathrm{mL}])+1.120 \times$ Loge $(\mathrm{INR})+0.643$

It was calculated at each follow up visit and value included in the study was of last visit ${ }^{17}$.

Exclusion criteria were the patients with less than 12 or more than 70 years of age or those with diagnosis of liver disease other than hepatitis C. Patients who had been diagnosed with or treated for HCC before the start of treatment or active alcohol users were also not included from the start. Patient who had hepatitis B infection along with HCV were also excluded from the analysis. Non responders to the routine anti-viral therapy were also made part of the exclusion criteria for this study.

Patients who were treated with antiviral therapy and received sustained viral response after HCV infection in the gastroenterology unit of PRREMH RWP fulfilling the above mentioned criteria of inclusion and exclusion were included in the study. Ethical committee of PEMH was approached for the approval before the start. 
These patients achieved sustained viral response at 24 weeks of the treatment. After that they were followed up three monthly for a period of two years. At each visit they underwent detailed clinical examination, relevant laboratory investigations (Blood complete picture, liver function test, renal function test and tumor marker if required) and ultrasonography of abdomen. Patients who had suspicion or positive findings on these tests underwent contrast enhanced CT scan to confirm the diagnosis of HCC. Genotype of the $\mathrm{HCV}$ was seen from the previous record and MELD score was calculated at the time of visit.

Statistics Package for Social Sciences version 24.0 (SPSS-24.0) was used for all the statistical analysis required for this study. Mean and standard deviation for the age of study participants was calculated. Chi-square and binary logistic regression analysis was performed to look for the association of age, gender, genotype of $\mathrm{HCV}$, presence of cirrhosis and MELD score with the diagnosis of HCC among the patients who had sustained viral response after the HVC treatment. $p$-value less than or equal to 0.05 was considered significant to establish the association between the variables.

\section{RESULTS}

One hundred and eighty six patients who achieved SVR after antiviral therapy were approached to get enrolled in the study after the included in the final analysis 121 were male and 49 were female. Mean age of patients enrolled in our study was 47.63 ( \pm 6.539$)$. Fifty three patients

Table-I: Characteristics of the study group and diagnosis of HCC.

\begin{tabular}{|c|c|c|c|}
\hline $\begin{array}{l}\text { Socio- } \\
\text { demographi } \\
\text { c factors } \\
\text { Total } \\
\text { n=170 }\end{array}$ & $\begin{array}{c}\text { Patients } \\
\text { without } \\
\text { diagnosis of } \\
\text { HCC } \\
\mathbf{n}(\%) \\
117(68.8)\end{array}$ & $\begin{array}{l}\text { Patients } \\
\text { with } \\
\text { diagnosis } \\
\text { of HCC } \\
\text { n ( } \%) \\
53(31.2)\end{array}$ & $\begin{array}{c}p- \\
\text { value }\end{array}$ \\
\hline \multicolumn{4}{|l|}{ Age } \\
\hline $\begin{array}{l}12-40 \text { year } \\
>40\end{array}$ & $\begin{array}{l}56(58.5) \\
61(41.5)\end{array}$ & $\begin{array}{l}24(25.8) \\
29(74.2)\end{array}$ & 0.755 \\
\hline \multicolumn{4}{|l|}{ Gender } \\
\hline $\begin{array}{l}\text { Male } \\
\text { Female }\end{array}$ & $\begin{array}{l}79(76.9) \\
38(23.1) \\
\end{array}$ & $\begin{array}{l}42(72.9) \\
11(27.1)\end{array}$ & 0.111 \\
\hline \multicolumn{4}{|c|}{ Genotype of HCV } \\
\hline $\begin{array}{l}\text { Genotype } 3 \\
\text { Other than } 3\end{array}$ & $\begin{array}{c}100(69.2) \\
17(30.1) \\
\end{array}$ & $\begin{array}{l}33(40) \\
20(60)\end{array}$ & 0.001 \\
\hline \multicolumn{4}{|c|}{ Presence of cirrhosis } \\
\hline $\begin{array}{l}\text { No } \\
\text { Yes }\end{array}$ & $\begin{array}{c}104(50.8) \\
13(49.1)\end{array}$ & $\begin{array}{l}30(37.6) \\
23(62.4)\end{array}$ & $<0.001$ \\
\hline \multicolumn{4}{|l|}{ MELD score } \\
\hline $\begin{array}{l}<15 \\
15 \text { or more }\end{array}$ & $\begin{array}{l}100(38.5) \\
17(61.5)\end{array}$ & $\begin{array}{l}31(47.1) \\
22(52.9)\end{array}$ & $<0.001$ \\
\hline
\end{tabular}

were diagnosed with the HCC in the given time while 117 were found negative on screening for the presence of malignancy. Thrity Six patients had the finding of cirrhosis on shear wave elastography. Other characteristics of study population have been summarized in table-I. Genotypes

Table-II: The correlated factors relating to the presence of HCC among the patients of HCV with SVR after the treatment: regression analysis.

\begin{tabular}{l|c|c} 
& $p$-value & OR (95\% CI) \\
\hline Age (ref. is 12 to 45 years) & 0.329 & $1.472(0.678-3.159)$ \\
\hline Gender (ref. is female) & 0.375 & $1.466(0.630-3.411)$ \\
\hline Genotype of HCV (ref. is <genotype 3) & 0.039 & $2.443(1.046-5.706)$ \\
\hline Presence of cirrhosis (ref. is no cirrhosis) & 0.004 & $3.917(1.554-9.871)$ \\
\hline MELD score (ref. is MELD score <15) & 0.011 & $2.936(1.282-6.727)$ \\
\hline
\end{tabular}

application of inclusion and exclusion criteria. Four of them did not give consent and refused to participate in the study while eleven were lost to follow up during the course of study and 1 patient died in this time after two follow ups due to myocardial infarction. Out of 170 patients other than 3, high MELD score and presence of cirrhosis were found linked with presence of HCC among these patients (table-I). Binary logistic regression analysis confirmed this association (table-II). 


\section{DISCUSSION}

Hepatitis virus has been an area of interest for clinicians as well as researchers in the last century. It has been a major threat to human life and still is due to its damaging effect to the liver which is a vital organ of human body. Hepatitis Virus exist in many forms, some have been benign and self-limiting while others have a lethal potential. Hepatitis $C$ has been one of those lethal types of the virus which slowly and gradually disrupts the architecture of liver and eventually fails the functioning capacity of this organ. Chronic liver disease and cirrhotic liver is one of the main complications of untreated $\mathrm{HCV}$ infection, HCC is another ${ }^{18}$. Level of suspicion is usually high among the physicians when the disease is advanced and untreated. Once direct anti-viral therapy has been used and sustained viral response is achieved, both patient and physician think that they have conquered the disease. This study was aimed to see the phenomenon which takes place after the achievement of this success and evaluate that either that success was transient or permanent.

Around thirty percent of our target population showed the presence of a newly emerged HCC in the course of two year follow up which we did for this study. This rate is very high as compared to the studies done in other parts of the world ${ }^{11-14}$. Reason might be searched at molecular level that either our population is predisposed to this damage even after the sustained viral response has been achieved or the virus genotype in our part of the world in more virulent as compared to other parts of the world. Whatever the reason may be, an alarming number of patients developed HCC after the apparent cure and control of the disease. This should be alarming for the treating physician and incorporated in the local guidelines for screening the individuals on regular basis after the sustained viral response has been achieved. If it is not possible to follow up all the cases, at least high risk cases depending upon the presence of risk factors should be screened.
Genotype of HCV has a strong link with presence of HCC in our population. There has already been a difference in genotype of virus around the globe. Genotype 1 has been common in the west and genotype 3 has been common in our part of the world 12,13 . Non 3 genotype has strong relation with presence of malignancy in our study. This finding is also difference from the findings of western studies ${ }^{12}$. This again highlights the difference at molecular level of both the patients and the causative organism. More research on local population may yield accurate information in this regard.

Presence of cirrhosis emerged as a strong risk factor for diagnosis of HCC among the patients included in our study. It can be a transitional phase between HCV infection and development of carcinoma after gross disruption of the liver architecture. Similar findings have been demonstrated in the past as well13. Few cases of HCC did not show presence of cirrhosis and distinct nodules were found on normal or coarse background liver architecture. More research is required in this regard to ascertain this association.

MELD score depicts that hoe severe liver problem is in the patient and is used to select the patients who immediately require liver transplant. High MELD score was significantly associated with the presence of HCC in the study participants. This finding has also been observed in other studies ${ }^{19}$. There could a bidirectional phenomenon; either underlying damaged liver was cause of raised MELD score as well as HCC or the presence of HCC has raised the MELD score at the time of calculation.

This study was not free from limitations. Many patients were lost to follow up so exact measure of the variables in the population could not be done. Follow up time was not that much long. Disruption of liver architecture is a slow process and may take years to develop HCC so cases which were declared disease free at the moment ay show the presence of HCC on long term follow up. Future studies with more sophis- 
ticated study designs and less dropout rates may generate more generalizable results on this topic.

\section{CONCLUSION}

Physicians and patients cannot ignore the possibility of a malignant outcome even after successful treatment of hepatitis C. Local protocols should be set for screening especially the high risk cases even after the treatment of $\mathrm{HCV}$ with special attention to patients with genotype other than 3, cirrhosis \& high MELD score on follow up visits.

\section{CONFLICT OF INTEREST}

There is no conflict of interest ti be declare by any author.

\section{REFERENCES}

1. Stasi C, Silvestri C, Voller F, Cipriani F. Epidemiology of Liver Cirrhosis. J Clin Exp Hepatol 2015; 5(3): 272.

2. Mukherjee PS, Vishnubhatla S, Amarapurkar DN, Das K, Sood A, Chawla YK, et al. Etiology and mode of presentation of chronic liver diseases in India: A multi centric study. PLoS One 2017; 12(10): e0187033.

3. Al Kanaani Z, Mahmud S, Kouyoumjian SP, Abu-Raddad LJ. The epidemiology of hepatitis $C$ virus in Pakistan: systematic review and meta-analyses. R Soc Open Sci 2018; 5(4): 180257.

4. Salamat A, Zubair UB, Shafqat H, Saeed F. Assessment of patients qualifying for liver transplant at a tertirary care hospital of Pakistan. Pak Armed Forces Med J 2012; 62(1): 1-5.

5. Kraus MR, Kleine H, Thönnes S, Pignot M, Sanchez Gonzalez Y. Improvement of hepatic and extrahepatic complications from chronic hepatitis $\mathrm{C}$ after antiviral treatment: a retrospective analysis of german sickness fund data. Infect Dis Ther 2018; 7(3): 339-52.

6. Ghouri YA, Mian I, Rowe JH. Review of hepatocellular carcinoma: Epidemiology, etiology, and carcinogenesis. J Carcinog 2017; 16(1): 1-6.

7. Zhu RX, Seto WK. Epidemiology of hepatocellular carcinoma in the asia-pacific region. Gut Liver 2016; 10(3): 332-39.
8. Tannus RK, Almeida-Carvalho SR, Loureiro-Matos CA, Miziara-Gonzalez A, Salzedas-Netto AA, Szejnfeld D, et al. Evaluation of survival of patients with hepatocellular carcinoma: A comparative analysis of prognostic systems. PLoS One 2018; 13(4): e0194922.

9. Umer M, Iqbal M. Hepatitis C virus prevalence and genotype distribution in Pakistan: Comprehensive review of recent data. World J Gastroenterol 2016; 22(4): 1684-700.

10. Colombo M, Lleo A. The impact of antiviral therapy on hepatocellular carcinoma epidemiology. Hepat Oncol 2018; 5(1): HEP03.

11. Morgan RL, Baack B, Smith BD, Yartel A, Pitasi M, Falck-Ytter Y. Eradication of hepatitis $C$ virus infection and the development of hepatocellular carcinoma: a meta-analysis of observational studies. Ann Intern Med 2013; 158(5 Pt 1): 329-37.

12. Alberti A, Piovesan S. Increased incidence of liver cancer after successful DAA treatment of chronic hepatitis C: Fact or fiction? Liver Int 2017; 37(6): 802-08.

13. Finkelmeier F, Dultz G, Peiffer KH, Kronenberger B, Krauss F, Zeuzem S, et al. Risk of de novo hepatocellular carcinoma after hcv treatment with direct-acting antivirals. Liver Cancer 2018; 7(2): 190-204.

14. Aleman S, Rahbin N, Weiland O, Davidsdottir L, Hedenstierna $\mathrm{M}$, Rose N, et al. A risk for hepatocellular carcinoma persists long-term after sustained virologic response in patients with hepatitis C-associated liver cirrhosis. Clin Infect Dis 2013; 57(2): 230-36.

15. Khaliq S, Raza SM. Current status of direct acting antiviral agents against hepatitis $\mathrm{C}$ virus infection in Pakistan. Medicina (Kaunas) 2018; 54(5): 80.

16. Shahnazarian V, Ramai D, Reddy M, Mohanty S. Hepatitis C virus genotype 3: clinical features, current and emerging viral inhibitors, future challenges. Ann Gastroenterol 2018; 31(5): 54151.

17. Samuel D, Coilly A. Management of patients with liver diseases on the waiting list for transplantation: a major impact to the success of liver transplantation. BMC Med. 2018; 16(1): 113.

18. Kraus MR, Kleine H, Thönnes S, Pignot M, Sanchez GY. Clinical and economic burden of hepatic and extrahepatic complications from chronic hepatitis $C$ : a retrospective analysis of german sickness fund data. Infect Dis Ther 2018; 7(3): 327-38.

19. Nacif LS, Paranagua-Vezozzo DC, Matsuda A, Alves VAF, Carrilho FJ, Farias AQ, et al. Higher values in liver elastography and MELD score are mortality predictors on liver transplant waiting. Arq Bras Cir Dig 2018; 31(1): e1360. 